\title{
Comparison of urinary biomarkers for prediction of acute kidney injury after coronary artery bypass surgery.
}

Author(s): Ashyralyyeva G, Sayılgan C, Yuceyar L, Erolcay H. Institute(s): Cerrahpasa Medical Faculty, Dept of Anesthesiology \& Intensive Care, Istanbul, Turkey

\section{Background and Goal of Study}

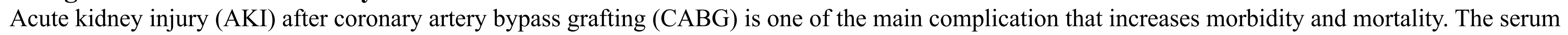

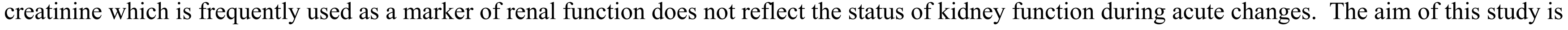
to assess the correlation between three urinary biomarkers [Microalbumine (MA), Neutrophil gelatinase-associated lipocalin (NGAL), Kidney injury molecule-1(KIM-1)] and AKI in CABG patients.

\section{Materials and Methods}

All elective CABG patients $>18$ years of age, underwent with cardiopulmonary bypass (CPB) between February 2016 and July 1016 were enrolled in the study. This prospective observational study was approved by the ethics committee of İstanbul University Cerrahpasa medical faculty. Exclusion criteria included preoperative presence of renal insufficiency defined as estimated GFR that was less than $60 \mathrm{~mL} / \mathrm{min} / 1.73 \mathrm{~m}^{2}$, critical preoperative conditions and emergency operations. The primary outcome was AKI, defined as $\geq \% 25$ decrease in glomerular filtration rate during the first 2 days after operation. The GFR was calculated as creatinine clearance rates with 24-hour urine collection. The single urine samples for MA and NGAL were obtained at postoperative 2-h and for KIM-1 at 24-h.

\section{Statistical analysis}

Statistical analysis was performed using SPSS software package version 24.0. All data were expressed as median (interquartile range IQR) and mean \pm standard deviation. Categorical variables were compared using chi-square or Fisher's exact test. Mann Whitney U test was used for non parametric variables. Spearman's correlation coefficient ( $r$ ) were calculated to analyze the correlation between biomarkers and length of stay in hospital and ICU. $\mathrm{P}<0,05$ was considered statistically significant.

\section{Results and Discussion}

A total of 70 patients were included in this study. AKI was identified in $18(\% 25.7)$ patients while other 52 patients (74.3) were classified as non-AKI. No significant differences were found between the two groups with respect to age, gender, body mass index, and duration of operation, CPB and aortic cross clamp time. The total postoperative bleeding rates and urine output did not differ among groups.

The MA, MA/Cr , NGAL and NGAL/Cr a were significantly higher in AKI patients than in non-AKI patients (Table 1). The length of stay in ICU and hospital were not different in two groups (Table 2). However, 2-h NGAL /Cr values correlated with length of stay in hospital and 2-h MA/ Cr measurements correlated with length of ICU stay (Table 3).

\section{Conclusion(s)}

Single measurements of urine NGAL and MA in 2-h after CABG may be useful for predicting the occurrence of AKİ while, urine KİM-1 which was measured in postoperative 24.hour was not associated with AKI.

Table 1. Urinary biomarker measurements after CABG surgery.

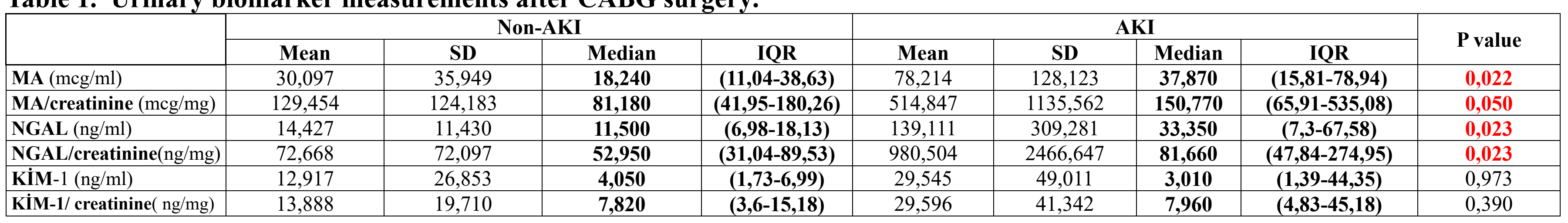

Table 2. Correlation between length of stay in ICU, hospital and AKI.

\begin{tabular}{|l|c|c|c|c|c|c|c|c|c|}
\hline & \multicolumn{5}{|c|}{ Non AKI } & \multicolumn{5}{c|}{ AKI } & $\begin{array}{c}\text { P } \\
\text { value }\end{array}$ \\
\cline { 2 - 10 } & Mean & SD & Median & IQR & Mean & SD & Median & IQR & \\
\hline $\begin{array}{l}\text { Length of } \\
\text { ICU stay } \\
\text { (hours) }\end{array}$ & 39,346 & 17,905 & $\mathbf{4 1}$ & $\begin{array}{c}\mathbf{( 2 4 -} \\
\mathbf{4 8})\end{array}$ & 61,444 & 44,51 & $\mathbf{4 4 , 5}$ & $\begin{array}{c}\mathbf{( 2 4 -} \\
\mathbf{9 2 , 2 5})\end{array}$ & 0,153 \\
\hline $\begin{array}{l}\text { Length of } \\
\text { hospital } \\
\text { stay } \\
\text { (days) }\end{array}$ & 10,096 & 6,878 & $\mathbf{7}$ & $\begin{array}{c}\mathbf{( 6 -} \\
\mathbf{1 1})\end{array}$ & 11,389 & 8,521 & $\mathbf{7 , 5}$ & $\begin{array}{c}\mathbf{( 6 , 7 5 -} \\
\mathbf{1 2 , 7 5})\end{array}$ & 0,634 \\
\hline
\end{tabular}

Table 3. Pearson correlation of biomarkers with length of stay of ICU and hospital.

\begin{tabular}{|c|c|c|c|}
\hline \multirow{2}{*}{ MA } & r & $\begin{array}{c}\text { Length of İCU } \\
\text { stay (hours) }\end{array}$ & $\begin{array}{c}\text { Length of hospital } \\
\text { stay (days) }\end{array}$ \\
\cline { 2 - 4 } & P value & 0,286 & 0,120 \\
\hline \multirow{2}{*}{ MA /Cr } & $\mathrm{r}$ & 0,016 & 0,321 \\
\cline { 2 - 4 } & P value & $\mathbf{0 , 0 2 0}$ & 0,106 \\
\hline \multirow{2}{*}{ NGAL } & $\mathrm{r}$ & 0,143 & 0,384 \\
\cline { 2 - 4 } & $\mathrm{P}$ value & 0,237 & 0,238 \\
\hline \multirow{2}{*}{ NGAL/Cr } & $\mathrm{r}$ & 0,097 & $\mathbf{0 , 0 4 8}$ \\
\cline { 2 - 4 } & P value & 0,425 & 0,243 \\
\hline \multirow{2}{*}{ KIM-1 } & $\mathrm{r}$ & $-0,005$ & $\mathbf{0 , 0 4 2}$ \\
\cline { 2 - 4 } & P value & 0,969 & $-0,184$ \\
\hline \multirow{2}{*}{ KIM1/Cr } & $\mathrm{r}$ & 0,037 & 0,126 \\
\cline { 2 - 4 } & P value & 0,762 & $-0,209$ \\
\hline
\end{tabular}

